\title{
Effects of plasma vaporization ablation on expression of inflammatory factors in rabbit model of intervertebral disc degeneration.
}

\author{
Tao Peng, Xiangyan Xu*, Guoqiang Shan, Hao Wang \\ Department of Orthopedics and Trauma, Shandong Provincial Hospital affiliated to Shandong University, Shandong, PR \\ China
}

\begin{abstract}
Intervertebral Disc Degeneration (IDD) is one common disease presented as wrist pain. Plasma vaporization ablation is a novel method treating IDD. This study utilized vaporization ablation on rabbit IDD model, whose expression of inflammatory factors was analysed along with the correlation with plasma vaporization ablation. Rabbit IDD model was generated by puncture approach and treated with plasma vaporization ablation. Control group received no treatment after surgery. MRI scanning was performed on rabbit intervertebral disc. Serum and intervertebral disc tissue samples were collected and tested for expression of Tumor Necrosis Factor $\alpha$ (TNF- $\alpha$ ), Interleukin-2 (IL-2) and IL-4 by Enzyme Linked Immunosorbent Assay (ELISA) or Immunohistochemistry (IHC) methods. $2 \mathrm{w}$ after puncture, rabbit had rupture of intervertebral disc fibrous ring, plus change of low-strength $T 2$ signal but not in T1 signal. $4 \mathrm{w}$ after surgery, model rats had further decreased intervertebral disc T2 signals. Both serum and intervertebral disc levels of TNF- $\alpha$, IL-2 and IL-4 were significantly elevated in model group, and were gradually decreased with elongated treatment $(p<0.05)$. Plasma vaporization ablation can decrease expression of TNF- $\alpha$, IL-2 and IL-4 in both serum and intervertebral disc tissues, probably forming one mechanism of IDD.
\end{abstract}

Keywords: Plasma vaporization ablation, Intervertebral disc degeneration, TNF- $\alpha$, IL-2, IL-4.

Accepted on October 27, 2017

\section{Introduction}

Intervertebral Disc Degeneration (IDD) is the major reason causing wrist pain. Spine will develop degenerative changes with aging, causing complicated motor dysfunction. During the whole process, cell biology, response load and body dysfunction all play important roles [1-3]. Previous study indicated the wide distribution of Tumor Necrosis Factor $\alpha$ (TNF- $\alpha$ ) and its receptor in neurons, with various biological functions including facilitating body blood clotting, elevating permeability of vascular endothelial cells, and enhancing expression of adhesion molecules and inflammatory related factors. TNF- $\alpha$ can facilitate occurrence of inflammation, and induce the entry of neurons into degenerative disc tissues, working as one neuromodulator with high expression level in those discs with degeneration [4-6]. Neural Stem Cells (NSCs) can differentiate into dopaminergic neurons, during which multiple signal pathways including Interleukin (IL) were involved. Previous study showed that interleukin can excite downstream signals after binding with respective receptors [7,8]. Plasma vaporization ablation was firstly proposed in 1990s. During this surgery, a blade is placed into targeted nucleus pulposus of intervertebral disc under percutaneous puncture. Part of nucleus pulposus tissues is removed via vaporization to depressurize intervertebral disc. Under the partial retraction of fibrous ring, further progression of intervertebral disc herniation can be impeded, thus depressurizing spinal and nerve tissues. Moreover, the destruction on neural fibers in that teared area within fibrous rings can relieve patient's pains $[9,10]$. In this study, a rabbit IDD model was generated for performing plasma vaporization ablation to test its effects on inflammatory related factors including TNF- $\alpha$, IL-2 and IL-4, in order to investigate the effect of plasma vaporization ablation on inflammatory factor expression in IDD, thus providing evidences for illustrating IDD pathogenesis.

\section{Materials and Methods}

\section{Experimental animals}

A total of 60 healthy rabbits (Rabbits were provided by Shandong University. 30 males and 30 females, body weight $2.5 \sim 3.5 \mathrm{~kg}$ ) were singly housed with food and water ad libitum.

Rabbits were used for all experiments, and all procedures were approved by the Shandong Provincial Hospital affiliated to Shandong University. 


\section{Equipment and reagent}

ELISA kits for TNF- $\alpha$, IL-2 and IL-4, rabbit anti-human TNF$\alpha$, IL-2 and IL-4 primary antibody, and goat anti-rabbit secondary antibody were purchased from Jianglai Chem (China). 3\% pentobarbital sodium, penicillin sodium, 10\% neutral buffered formalin and hematoxylin-eosin dye were purchased from China Pharma (China). MRI scanner was a product of Philips (Netherland). Microtome was purchased from Leica (Germany). Plasma apparatus was purchased from ArthroCare Corp (US).

\section{Generation of rabbit IDD modeI}

All rats were housed in the animal house. 30 rabbits were selected to create IDD model. In brief, animals were anesthetized in 3\% pentobarbital sodium and were fixed in four limbs. After general sterilization, an incision was made from the cleft between obliquus externus abdominis and longissimus muscle on right side to separate muscles and to expose spinal tissues. On the right side of intervertebral disc, two frontier edge of spines were exposed. Fibrous rings were punctured by $16 \mathrm{G}$ needles. After injury, the needle was kept still for $5 \mathrm{~s}$, followed by trauma suture. MRI examination was performed at $2 \mathrm{w}$ and $4 \mathrm{w}$ post-op to observe T2 signals in coronal sections. IDD condition was divided into grade I (normal), grade II (minor weakening and shrinking of high signal area), grade III (moderate weakening of signals) and grade IV (severely decreased signals).

\section{Animal grouping}

Model and normal rabbits were all divided into control and experiment groups, which were marked as A and B. Model experimental group A: rabbit ID model was generated by needle puncture, followed by plasma vaporization ablation. Model control group A: IDD model was generated without further intervention. Normal experimental group A: Sham surgery was performed followed by plasma vaporization ablation. Normal control group A: Sham surgery without intervention.

\section{Plasma vaporization ablation}

All animals were treated on plasma apparatus, whose blade tail targeted 12 o'clock orientation. A vaporization ablation cycle was performed from the distal site toward the retraction to origins. Perforated ablation was performed at 6 orientations in a clockwise sequence. After ablation, blade and puncture cannula were sequentially retracted for layered suture.

\section{Serum TNF- $\alpha, I L-2$ and $I L-4$ assays by ELISA}

Peripheral venous blood samples were collected $1 \mathrm{~d}, 1 \mathrm{w}$ and 2 $\mathrm{w}$ after surgery. Blood samples were centrifuged to collect the supernatant. Standard wells were set on microplate reader. After adding dilution buffer, the plate was incubated at $37^{\circ} \mathrm{C}$ for $30 \mathrm{~min}$. The supernatant was discarded, followed by washing and drying. Chromogenic substrates A and B were sequentially added for $37^{\circ} \mathrm{C}$ for $15 \mathrm{~min}$ to develop the membrane. After reaction terminating, absorbance value was measured from each well at $450 \mathrm{~nm}$ wavelength.

\section{Expression of TNF- $\alpha, I L-2$ and $I L-4$ in intervertebral disc tissues}

Rabbits were sacrificed at $1 \mathrm{~d}, 1 \mathrm{w}$ and $2 \mathrm{w}$ after surgery. Samples were collected and weighted. Tissues were fixed in formalin, dehydrated, embedded, sectioned. Citric acid was added for antigen retrieval, followed by hydrogen peroxidase blocking and goat serum blocking. Primary antibody (1:100 dilutions) was added for $1 \mathrm{~h}$ incubation, followed by $10 \mathrm{~min}$ incubation in secondary antibody. The slide was developed, quenched, counter-stained, differentiated and mounted.

Judgement criteria of TNF- $\alpha$, IL-2 and IL-4 [10]: Positive was defined as no nuclear staining, plus yellow to brown granules on membrane or cytoplasm. Staining grade was classified as percentage of positively staining cells. Negative $(-) \leq 10 \%$; Weak positive $(+) 11 \% \sim 25 \%$; positive $(++)$ was defined when positive cell ratio between $26 \%$ and $50 \%$; strong positive $(+++)$ when positive cells are more than $40 \%$

\section{Data processing}

SPSS17.0 software was used for data processing. Enumeration data were compared by chi-square method, whilst measurement data were analysed in ANOVA. Data were presented as mean \pm Standard Deviation (SD). A statistical significance was defined when $\mathrm{p}<0.05$.

\section{Results}

\section{MRI scanning for rabbit intervertebral disc}

Rabbit IDD model was generated by puncture into the left anterior fibrous ring at pyramidal region. Two weeks later, intervertebral fiber was ruptured, showing change of low strength $\mathrm{T} 2$ signals at posterior edge of fibrous ring. $4 \mathrm{w}$ later, model rabbits showed further suppression of wrist T2 signals (grade IV). After applying Plasma vaporization ablation, MRI was performed to observe the change of intervertebral disc and found enhanced wrist grade II T2 signal compared to those before surgery (Figure 1).

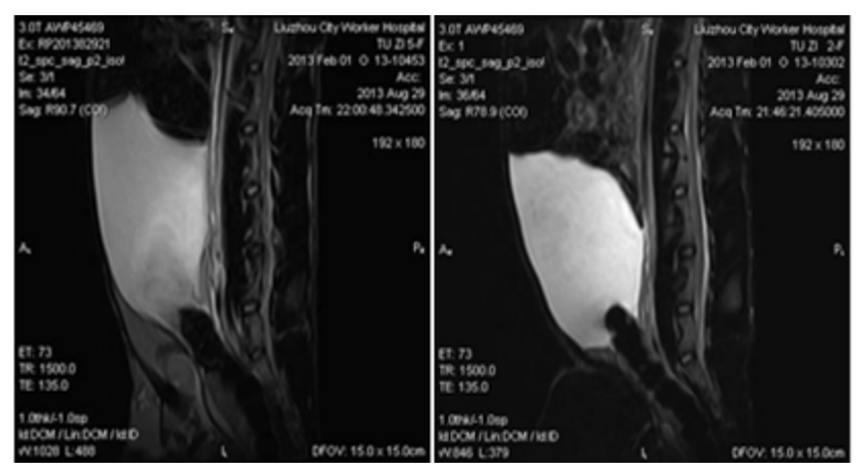

Figure 1. MRI scanning of rabbit intervertebral disc after plasma vaporization ablation (left) and in IDD model group (right). 
Effects of plasma vaporization ablation on expression of inflammatory factors in rabbit model of intervertebral disc degeneration

\section{Serum TNF- $\alpha, I L-2$ and IL-4 levels}

We measured serum levels of TNF- $\alpha$, IL-2 and IL-4 in all rabbits. At 1 day, 1 week and 2 weeks post-op, serum TNF- $\alpha$, IL-2 and IL-4 levels were all elevated $(\mathrm{p}<0.05$ compared to control group). Model experimental group A had higher serum TNF- $\alpha$, IL-2 and IL-4 levels were higher than model control group $(\mathrm{p}<0.05)$. With elongated time, model experimental group A had gradually decreased TNF- $\alpha$, IL-2 and IL-4 levels $(\mathrm{p}<0.05$, Table 1$)$.

\section{$T N F-\alpha, I L-2$ and $I L-4$ expression in intervertebral disc}

We further measured TNF- $\alpha$, IL-2 and IL-4 expressions in rabbit intervertebral disc tissues at $2 \mathrm{w}$ post-up. Results showed elevated expression of TNF- $\alpha$, IL-2 and IL-4 in intervertebral disc tissues from model group ( $\mathrm{p}<0.05$ compared to control group). Model experimental group had higher indexes compared to model control group at $2 \mathrm{w}$ post-op $(\mathrm{p}<0.05)$. No significant difference existed between normal experimental and normal control group ( $p>0.05$, Table 2 and Figures 2-4).
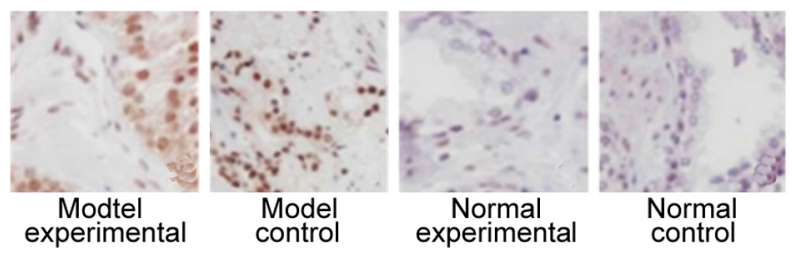

Figure 2. TNF- $\alpha$ expression in rabbit intervertebral disc tissues (X400). (A) Model experimental group; (B) Model control group; (C) Normal experimental group; (D) Normal control group.

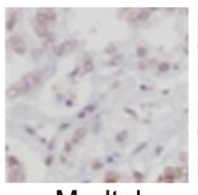

Modtel experimental
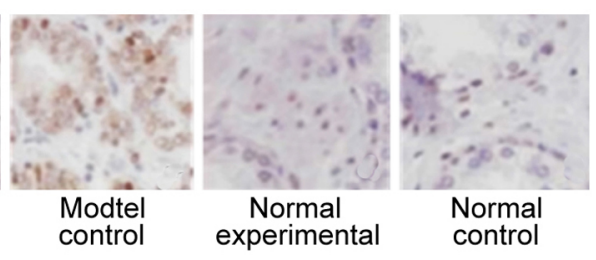

Figure 3. IL-2 expression in rabbit intervertebral disc tissues (X400). (E) Model experimental group; (F) Model control group; (G) Normal experimental group; (H) Normal control group.
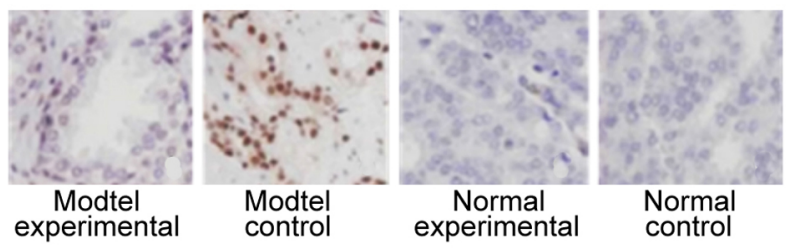

Figure 4. IL-4 expression in rabbit intervertebral disc tissues (X400). (I) Model experimental group; (J) Model control group; (K) Normal experimental group; (L) Normal control group.

Table 1. Serum levels of TNF- $\alpha, I L-2$ and $I L-4(n g / m l)$.

\begin{tabular}{|c|c|c|c|c|c|}
\hline Group & $\mathbf{N}$ & TNF- $\alpha$ & & IL-2 & IL-4 \\
\hline $\begin{array}{l}\text { Model } \\
\text { experimental }\end{array}$ & 15 & & & & \\
\hline $1 \mathrm{~d}$ post-op & & $184.78 \pm 5.43$ & & $6.45 \pm 0.23$ & $4.53 \pm 0.43$ \\
\hline $1 \mathrm{w}$ post & & $154.32 \pm 4.66$ & & $3.01 \pm 0.11$ & $2.82 \pm 0.25$ \\
\hline $2 w$ & & $\begin{array}{l}141.46 \\
8.52^{1,2,3,4,5}\end{array}$ & \pm & $\begin{array}{l}1.23 \\
0.08^{1,2,3,4,5}\end{array}$ & $\begin{array}{l}1.31 \\
0.12^{1,2,3,4,5}\end{array}$ \\
\hline Model control & 15 & & & & \\
\hline $1 \mathrm{~d}$ post-op & & $195.78 \pm 10.82$ & & $5.87 \pm 0.22$ & $4.57 \pm 0.36$ \\
\hline $1 \mathrm{w}$ post & & $196.43 \pm 12.80$ & & $6.92 \pm 0.35$ & $5.23 \pm 0.41$ \\
\hline $2 w$ & & $\begin{array}{l}225.76 \\
11.38^{2,3,4,5}\end{array}$ & \pm & $7.51 \pm 0.432345$ & $6.33 \pm 0.45^{2,3,4,5}$ \\
\hline $\begin{array}{l}\text { Normal } \\
\text { experimental }\end{array}$ & 15 & & & & \\
\hline $1 \mathrm{~d}$ post-op & & $90.23 \pm 5.56$ & & $1.26 \pm 0.12$ & $1.16 \pm 0.13$ \\
\hline $1 \mathrm{w}$ post & & $88.45 \pm 4.37$ & & $0.95 \pm 0.08$ & $1.01 \pm 0.09$ \\
\hline $2 w$ & & $87.33 \pm 5.84$ & & $0.42 \pm 0.05$ & $0.86 \pm 0.06$ \\
\hline Normal control & 15 & & & & \\
\hline $1 \mathrm{~d}$ post-op & & $91.18 \pm 4.36$ & & $1.38 \pm 0.14$ & $1.21 \pm 0.15$ \\
\hline $1 \mathrm{w}$ post & & $91.78 \pm 5.25$ & & $1.01 \pm 0.11$ & $1.13 \pm 0.13$ \\
\hline $2 w$ & & $93.33 \pm 5.45$ & & $0.86 \pm 0.07$ & $1.01 \pm 0.08$ \\
\hline
\end{tabular}

Note: ${ }^{1} p<0.05$ compared to model control group; ${ }^{2} p<0.05$ compared to normal experimental group; ${ }^{3} p<0.05$ compared to normal control; ${ }^{4} p<0.05$ compared to $1 \mathrm{~d}$ post-op; ${ }^{5} \mathrm{p}<0.05$ compared to $1 \mathrm{w}$ post-op.

Table 2. TNF- $\alpha, I L-2$ and IL-4 expression in rabbit intervertebral disc tissues.

\begin{tabular}{|c|c|c|c|c|}
\hline Index & Model experimental $(n=15)$ & Model control $(n=15)$ & Normal experimental $(n=15)$ & Normal control $(n=15)$ \\
\hline \multicolumn{5}{|l|}{ TNF- $\alpha$ expression } \\
\hline - & 6 & 3 & 14 & 13 \\
\hline+-++ & 4 & 5 & 1 & 2 \\
\hline+++ & 5 & 7 & 0 & 0 \\
\hline Positive rate $(\%)$ & $60^{1,2,3}$ & $80^{2,3}$ & 6.7 & 13.3 \\
\hline \multicolumn{5}{|l|}{ IL-2 expression } \\
\hline- & 7 & 4 & 14 & 14 \\
\hline
\end{tabular}




\begin{tabular}{|c|c|c|c|c|}
\hline+-++ & 3 & 4 & 1 & 1 \\
\hline+++ & 5 & 7 & 0 & 0 \\
\hline Positive rate (\%) & $53.3^{1,2,3}$ & $73.3^{2,3}$ & 6.7 & 6.7 \\
\hline \multicolumn{5}{|l|}{ IL-4 expression } \\
\hline- & 6 & 4 & 14 & 13 \\
\hline+-++ & 4 & 4 & 1 & 2 \\
\hline+++ & 5 & 7 & 0 & 0 \\
\hline Positive rate (\%) & $60^{1,2,3}$ & $73.3^{2,3}$ & 6.7 & 13.3 \\
\hline
\end{tabular}

Note: ${ }^{1} p<0.05$ compared to model control group; ${ }^{2} p<0.05$ compared to normal experimental group; ${ }^{3} p<0.05$ compared to normal control.

\section{Discussion}

Occurrence and progression of IDD are relatively slow, causing instability of body spines. IDD pathogenesis is affected by various factors including genes, life styles, biophysics, and other chronic diseases, making it one complicated and refractory disease that severely affect patient's health and life quality [11]. In clinics, major approaches for treating IDD include surgery, conservative treatment, cell therapy or gene therapy, all of which may not achieve satisfactory results [12]. Plasma vaporization ablation is one novel technology that can transmit intense energy to form one plasma zone with highly condensed ionized particles, which have tremendous energy to directly destruct molecular bindings $[13,14]$. In this study, we generated a rabbit IDD model, on which plasma vaporization ablation was performed to test the effect on the expression of inflammatory factors such as TNF- $\alpha$, IL-2 and IL-4, in order to investigate the effect of plasma vaporization ablation in treating IDD-induced wrist pain and pathogenesis mechanism.

In this study, we firstly generated a rabbit IDD model via needle puncture against spinal fibrous rings. Two weeks later, the fibrous ring of rabbit intervertebral disc was ruptured, as shown by change of low strength T2 signal. Four weeks after surgery, model rats had further lower $\mathrm{T} 2$ signal in rabbit wrist intervertebral disc to reach level 4 signal. After plasma vaporization ablation treatment, MRI was performed to observe the change of intervertebral disc, which was found to have enhanced T2 signals compared to model animals. T2 signal reached grade 2, which was improved compared to before surgery.

TNF is one cytotoxic factor that can directly kill tumor cells. TNF- $\alpha$ is produced by activated mononuclear cells and has pluripotent biological functions including anti-viral functions or anti-infection $[15,16]$. Some studies showed the important role of inflammatory roles including TNF- $\alpha$, IL-2 and COX-2 in occurrence and progression of IDD $[17,18]$. In this study, we tested serum levels of TNF- $\alpha$, IL- 2 and IL- 4 in all rabbits. Results showed higher serum TNF- $\alpha$, IL-2 and IL-4 levels in model animals at $1 \mathrm{~d}, 1 \mathrm{w}$ and $2 \mathrm{w}$ after surgery. Model experimental group had higher serum TNF- $\alpha$, IL-2 and IL-4 levels than model control group. With elongated time, model experimental group had gradually decreased serum TNF- $\alpha$, IL-2 and IL-4 levels. These results indicated higher serum TNF- $\alpha$, IL-2 and IL-4 levels in IDD rabbits. Plasma vaporization ablation effectively decreased serum TNF- $\alpha$, IL-2 and IL-4 levels in IDD rabbits. Such decreasing trends were more significant with elongated treatment time.

Further study collected intervertebral disc tissues, on which expression of TNF- $\alpha$, IL-2 and IL- 4 were measured at $2 \mathrm{w}$ after surgery. Results showed elevated TNF- $\alpha$, IL-2 and IL-4 expressions in model group compared to control group. Model experimental group had higher TNF- $\alpha$, IL-2 and IL-4 expression in intervertebral disc tissues compared to those in model control group. These results suggested that plasma vaporization ablation can decrease expression of TNF- $\alpha$, IL-2 and IL-4 expression in intervertebral disc tissues. Previous study indicated significantly elevated TNF- $\alpha$ expression in degenerative intervertebral disc tissues compared to normal tissues [19]. Some study has established a rabbit IDD model by injection of TNF- $\alpha$ into intervertebral disc. Further assay showed the positive correlation between degeneration of intervertebral disc and TNF- $\alpha$ expression in intervertebral disc tissues [20]. Genetics study showed consistent gene frequency of polymorphism in all IDD patients compared to normal controls [21,22]. These results showed the critical role of inflammatory factor for progression of IDD.

\section{Conclusion}

In IDD rabbits, expression levels of TNF- $\alpha$, IL-2 and IL-4 in both serum and intervertebral disc tissues were elevated. Plasma vaporization ablation can decrease TNF- $\alpha$, IL- 2 and IL-4 expression in both serum and intervertebral disc tissues of IDD rabbits, possibly forming one important mechanism treating IDD. However, IDD is one complicated motor dysfunction, whether expression of TNF- $\alpha$, IL-2 and IL-4 are correlated with neurons or other neural injury markers, or are involved in IDD occurrence or progression, are worth for further investigation.

\section{References}

1. Freedhoff Y. Controversy surrounds new treatment for discogenic back pain. CMAJ 2010; 182: 409-410. 


\section{degeneration}

2. Freemont AJ. The cellular pathobiology of the degenerate intervertebral disc and discogenic back pain. Rheumatology (Oxford) 2009; 48: 5-10.

3. Lierz P, Alo KM, Felleiter P. Percutaneous lumbar discectomy using the Dekompressor system under CTcontrol. Pain Pract 2009; 9: 216-220.

4. Choy DS, Hellinger J, Hellinger S, Tassi GP, Lee SH. 23rd Anniversary of Percutaneous Laser Disc Decompression (PLDD). Photomed Laser Surg 2009; 27: 535-538.

5. Tassi GP, Preliminary Italian experience of lumbar spine percutaneous laser disc decompression according to Choys method. Photomed Laser Surg 2004; 22: 439-441.

6. Schizas C, Kulik G, Kosmopoulos V. Disc degeneration: current surgical options. Eur Cell Mater 2010; 20: 306-315.

7. Yu LZ, Wang HY, Yang SP, Yuan ZP, Xu FY, Sun C, Shi RH. Expression of interleukin-22/STAT3 signaling pathway in ulcerative colitis and related carcinogenesis. World J Gastroenterol 2013; 19: 2638-2649.

8. Cua DJ, Tato CM. Innate IL-17-producing cells: the sentinels of the immune system. Nat Rev Immunol 2010; 10: 479-489.

9. Gruber HE, Hoelscher GL, Ingram JA, Bethea S, Hanley EN. Growth and differentiation factor-5 (GDF-5) in the human intervertebral annulus cells and its modulation by IL-1ss and TNF-alpha in vitro. Exp Mol Pathol 2014; 96: 225-229.

10. Gupta R, Bathen ME, Smith JS, Levi AD, Bhatia NN. Advances in the management of spinal cord injury. $\mathrm{J}$ Am Acad Orthop Surg 2010; 18: 210-222.

11. Vo N, Seo HY, Robinson A, Sowa G, Bentley D, Taylor L, Studer R, Usas A, Huard J, Alber S, Watkins SC, Lee J, Coehlo P, Wang D, Loppini M, Robbins PD, Niedernhofer LJ, Kang J. Accelerated aging of intervertebral discs in a mouse model of progeria. J Orthop Res 2010; 28: 1600-1607.

12. Lee SH, Derby R, Sul D, Hong J, Kim GH, Kang S, Kim NH, Yoo SH, Lee SJ, Hong YK, Lee JE. Efficacy of a new navigable percutaneous disc decompression device (LDISQ) in patients with herniated nucleus pulposus related to radicular pain. Pain Med 2011; 12: 370-376.

13. Manchikanti L, Cash KA, McManus CD, Pampati V, Smith HS. One-year results of a randomized, double-blind, active controlled trial of fluoroscopic caudal epidural injections with or without steroids in managing chronic discogenic low back pain without disc herniation or radiculitis. Pain Physician 2011; 14: 25-36.
14. Peng B, Pang X, Wu Y, Zhao C, Song X. A randomized placebo-controlled trial of intradiscal methylene blue injection for the treatment of chronic discogenic low back pain. Pain 2010; 149: 124-129.

15. Erbil G, Yurtsever C, Sonmez U. Histological and biochemical findings in an experimental model of intervertebral disc degeneration based on radio frequency. $\mathrm{J}$ Neurol Sci Turkish 2008; 25: 208-219.

16. Kabbara A, Hayek S. Intradiscal electrothermal therapy (IDET) for the treatment of discogenic pain. Tech Reg Anesth Pain Manag 2009; 13: 102-108.

17. Papadopoulos D, Kostopanagiotou G, Lemonis A, Batistaki C. Intradiscal combination of pulsed radiofrequency and gelified ethanol for the treatment of chronic discogenic low back pain. Pain Med 2014; 15: 881-883.

18. Liu ZH, Miao GS, Wang JN, Yang CX, Fu ZJ, Sun T. Resolvin D1 inhibits mechanical hypersensitivity in sciatica by modulating the expression of nuclear factor-kappaB, phospho-extracellular signal-regulated kinase, and pro- and antiinflammatory cytokines in the spinal cord and dorsal root ganglion. Anesthesiology 2016; 124: 934-944.

19. Malik KM, Cohen SP, Walega DR, Benzon HT. Diagnostic criteria and treatment of discogenic pain: a systematic review of recent clinical literature. Spine J 2013; 13: 1675-1689.

20. Lee SC. Percutaneous intradiscal treatments for discogenic pain. Acta Anaesthesiol Taiwan 2012; 50: 25-28.

21. Manchikanti L, Derby R, Benyamin RM, Helm S, Hirsch JA. A systematic review of mechanical lumbar disc decompression with nucleoplasty. Pain Physician 2009; 12: 561-72.

22. Kapural L, Cata JP, Narouze S. Successful treatment of lumbar discogenic pain using intradiscal biacuplasty in previously discectomized disc. Pain Pract 2009; 9: 130-134.

\section{*Correspondence to}

Xiangyan Xu

Department of Orthopedics and Trauma

Shandong Provincial Hospital affiliated to Shandong University

PR China 